\title{
Fire drill: Inattentional blindness and amnesia for the location of fire extinguishers
}

\author{
Alan D. Castel • Michael Vendetti • Keith J. Holyoak
}

Published online: 8 August 2012

(C) Psychonomic Society, Inc. 2012

\begin{abstract}
Fire extinguishers can save lives and are placed in locations that make them easily accessible and in plain view in case of an emergency. However, despite having viewed these bright red objects many times, people may be unaware of their precise locations or even of the fact that they have seen them so often in their workplace environment. We tested the ability of occupants of an office building to recall the location of the nearest fire extinguisher, as well as other objects (e.g., clock, drinking fountain). Despite years of exposure to it, a majority failed to remember the location of the nearest fire extinguisher, although they were able to locate it relatively quickly when asked to search for it. The results support an important distinction between seeing and noticing objects and reveal a novel form of inattentional amnesia for salient objects. The study also created an important learning event via failed retrieval, which could be essential to survival.
\end{abstract}

Keywords Memory · Attention · Inattentional blindness · Amnesia $\cdot$ Fire safety

Do you know where the nearest fire extinguisher is? In a workplace environment, fire extinguishers are placed in locations that make them easily accessible and in plain view, such that they can be quickly located (situated within 75 feet of employees, according to the United States Department of Labor Occupational Safety and Health Administration, 2012). However, despite having viewed these bright red objects many times, people may be unaware of their precise locations or even of the fact that they have seen them so often. In the domain of visual attention and memory, there

\footnotetext{
A. D. Castel $(\bowtie) \cdot M$. Vendetti $\cdot$ K. J. Holyoak Department of Psychology, University of California, Los Angeles, 1285 Franz Hall, Box 951563, Los Angeles, CA 90095, USA e-mail: castel@ucla.edu
}

have been several powerful demonstrations of inattentional blindness, in which people do not see objects when they are directing attention to other locations (Mack \& Rock, 1998). Strikingly, Simons and Chabris (1999) have shown that people will often fail to notice a gorilla walk through a scene if they are busy attending to other aspects of the scene. Similarly, Simons and Rensink (2005) have shown demonstrations of change blindness, where people often do not notice a change in a scene, even when this change occurs with previously studied objects that are in the focus of attention. Wolfe (1999) has suggested that inattentional amnesia occurs when people have previously seen the objects in question but do not have a specific memory for having seen these objects, possibly due to a failure of attentional control and interruption in encoding the objects in memory.

On the basis of this previous work, as well as our own recent experiences (see Fig. 1 and caption), we were interested in whether people could accurately remember and locate the nearest fire extinguisher in their workplace setting, and, critically, whether people may display impairments in being able to remember and locate these highly visible and potentially lifesaving devices. If so, this would constitute an interesting example of inattentional blindness and/or lack of memory for highly visible objects, perhaps explicable by the influence of goal-directed attention processes on memory. In this case, we use the term inattentional amnesia to characterize instances where people have been repeatedly exposed to the location of the fire extinguishers but experience long-term memory failure for the correct location of this previously seen object. Furthermore, as was emphasized by Kingstone, Smilek, Ristic, and Eastwood (2003), it is important to determine whether inattentional blindness and inattentional amnesia play a significant role in real-world settings (see also Neisser, 1982), particularly in situations that involve the potential to prevent injuries or even save lives. 


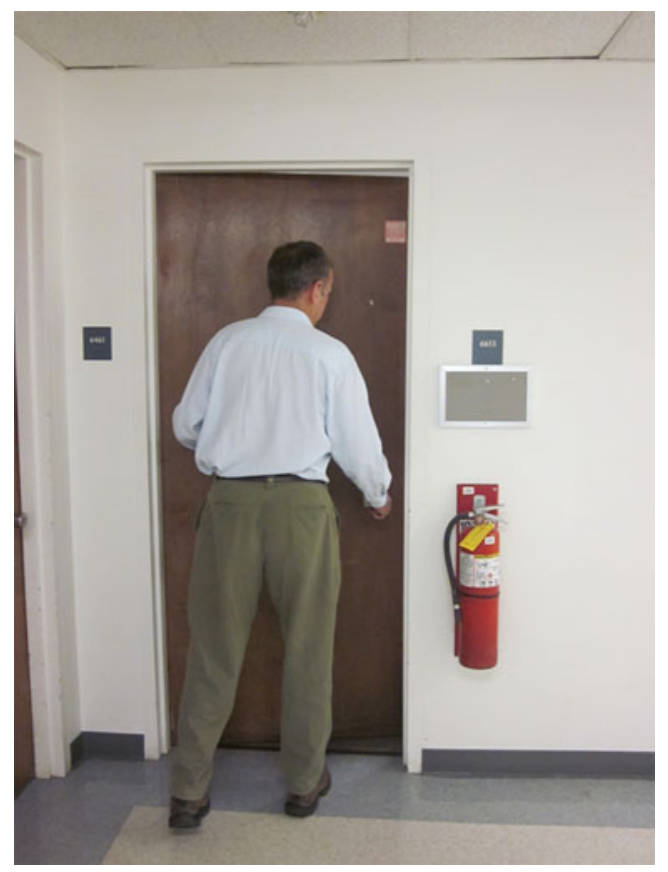

Fig. 1 The location of a fire extinguisher relative to an office door in the present study. The present study was partially inspired by the observation, recently illustrated by one of the authors of the present article (depicted above), that we are remarkably good at ignoring highly visible objects and remarkably bad at remembering their location. While teaching a building safety class, the fire safety instructor asked people to note the location of the nearest fire extinguisher, relative to their office. In the class, several people admitted that they did not know the location or guessed at the location, and people were told they should learn the location of the nearest fire extinguisher. Upon returning to his office, one of the authors of the present article (K.H.) made a conscious effort to look for the nearest fire extinguisher and made a startling discovery: The conspicuously placed bright red object in question was right next to his office door, in plain view, and literally inches from the door knob that he had turned for the past 25 years!

Is it possible people really do not notice potentially lifesaving safety devices that are designed to be located in plain view and to be easily accessible? To determine whether this is the case, we conducted a field study of university faculty, staff, and students who had offices in the Psychology Department building (Franz Hall tower) at the University of California, Los Angeles (UCLA). Participants were approached in their offices and were asked whether they knew the location of the nearest fire extinguisher. They were also asked to rate their confidence in knowing the nearest location and were then asked to exit their office and locate the nearest fire extinguisher. We hypothesized that if inattentional amnesia and inefficiencies in visual search influence how we locate and remember objects in real-world settings (e.g., Kingstone, Smilek, Birmingham, Cameraon, \& Bischof, 2005; Vo \& Wolfe, 2012; Wolfe, Horowitz, \& Kenner, 2005; Wolfe, Alvarez, Rosenholtz, \& Kuzmova, 2011), then there may be striking instances in which people fail to remember and find the location of the nearest fire extinguisher, a failure of memory that could have important safety implications. In addition, we conducted a follow-up interview approximately 2 months after the initial study, to determine whether participants were able to locate other common objects (floor plan map, clock, drinking fountain, fire alarm) and to determine whether they could accurately remember the location of the previously tested fire extinguisher. We were interested in the degree to which the location of more frequently used objects would be remembered and, in the case of recalling the location of the fire extinguisher, whether the potential failed-retrieval during the initial test might facilitate later retention after a 2month retention interval.

\section{Method}

\section{Participants and locale}

Participants in the initial session were 54 faculty, staff and students in the UCLA Department of Psychology, located in Franz Hall tower. In total, 20 full-time faculty or post doctoral fellows, 24 graduate students, and 10 staff participated in the study. The mean age of the participants was 34.2 years (range, 21-76 years of age), 52\% were female, and the mean number of years that each person had occupied their office was 4.9 years (range, $0.5-42$ years). Floors 3-8 of the Franz Hall tower were chosen because they all had similar spatial layouts, with each floor having six fire extinguishers in plain sight (see Fig. 2). The distance of the nearest fire extinguisher to the office door of building occupants ranged from approximately 1 foot to 25 feet. In many cases, two or more fire extinguishers were located in plain view from the doorways of offices. By coincidence, the study was conducted 1 week after a fire drill in which all occupants had been required to vacate the building (but no one was required to find or use a fire extinguisher).

\section{Procedure and materials}

People were approached while in their office or laboratory and were asked whether they would complete a short survey about building safety. They were then asked whether they specifically knew where the closest fire extinguisher was (yes or no), and how confident they were about knowing the location (on a scale of $0-10$, with 10 indicating extremely high confidence). They were then asked to get up and leave their office to find the nearest fire extinguisher. After recording whether they had known exactly where to initially look and whether they found it within a 5-to 10-s range, we then asked whether they had noticed it in this location before (yes or no) and whether they were at all surprised 


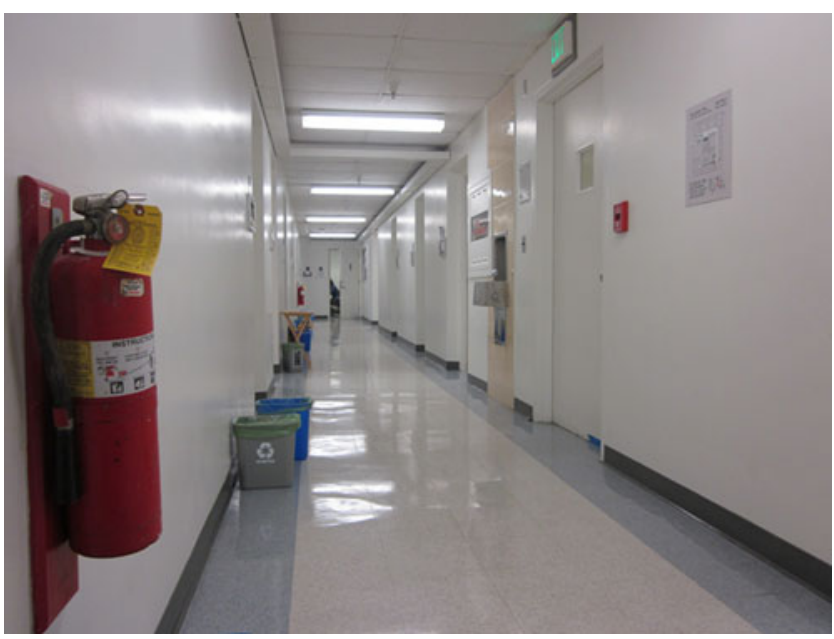

Fig. 2 A typical hallway layout in Franz Hall. The location of several fire extinguishers (two attached to wall on the left, at opposite ends of hallway; a third enclosed in a glass case on the right wall just past the water fountain, with "FIRE EXTINGUISHER" emblazoned in large red letters on the surface of the glass). Also visible are a drinking fountain (next to the encased fire extinguisher), floor plan (posted on wall, at right), and fire alarm (between floor plan and drinking fountain)

about knowing/not knowing the location, now that they had actually located it. Finally, we asked them how confident they were that they could find the fire extinguisher at some point in the future. Participants were then asked to provide some background information, including age, number of years in this office, and position (faculty, staff, or student). They then were debriefed about the study and were asked whether they had any questions or comments.

We also conducted a surprise follow-up interview 2 months after the initial study, in which we tested an available subset of participants from the initial session $(n=35)$. We asked participants whether they knew the location of other common objects that were present in each hallway in plain view and were used to varying degrees (floor plan map, clock, drinking fountain), as well as the nearest fire alarm and the previously tested fire extinguisher. Participants indicated whether they knew the correct location of each object and reported their confidence and how often they used the object (where applicable). They were then asked to locate each object in any order, and we assessed approximately how long it took to find each object (see Fig. 2 and Table 1 for more information about the objects' frequency and locations).

\section{Results and discussion}

Of the 54 people we tested in the initial study, only 13 (24\% of the sample) could accurately tell us the location of the nearest fire extinguisher, and 8 people specified a fire extinguisher that was not the nearest one (see Fig. 3). However, when asked to physically locate the nearest first extinguisher, $92 \%$ of the participants found a fire extinguisher within $5 \mathrm{~s}$ of exiting their office. Over half of the participants were surprised that they had never noticed the location of the nearest fire extinguisher, since it was situated in a place where they must have seen it many times (e.g., near their door, directly across the hall). Accuracy was not significantly correlated with age or number of years in the office location. Ratings of initial confidence in knowing the nearest location were generally low $(M=4.4)$, but after the nearest fire extinguisher had been found, confidence in being able to find this fire extinguisher at a future time $(M=9.5)$, was significantly higher, as confirmed by a Wilcoxon test, $T=-4.77, p<.0001$. Initial confidence ratings were correlated with accurately locating the nearest fire extinguisher, Spearman's $\rho=.61, p<.001$, suggesting that people have some metacognitive awareness of knowing/not knowing the location of the nearest fire extinguisher.

Those who answered correctly provided a variety of reasons as to why they knew the location of the nearest fire extinguisher. For example, 3 people who accurately knew the location of the nearest fire extinguisher said that they had viewed it many times and that that was why they knew the location; 3 people had recently taken a laboratory safety training course; and 2 people had some specific memories associated with it (e.g., an unusual chair was always next to it, or they knew someone had hidden a key there in the past). Eight people located a fire extinguisher, but it was not the nearest fire extinguisher to their office (e.g., they initially walked past the nearest fire extinguisher while locating one that was farther away). After being informed that there was, in fact, a closer fire extinguisher, they quickly found it (and were surprised by the location). Several people also remarked that it was probably near the elevator (even if one was much closer), suggesting that sometimes people infer the locations, have a general or "gist-based" notion, or misremember certain aspects, without relying on actual memory for a specific (nearest) location (cf. Bartlett, 1932; Intraub \& Richardson, 1989; Loftus, 1992; Wolfe, 1998). In general, many people were initially surprised that they did not know the location of the nearest fire extinguisher, and upon finding it themselves, they were also surprised that they had not noticed it there before (for example, several people asked, "Has it always been there?"). Twelve people remarked that they had "seen" the location before but had not "noticed" the fire extinguisher. This finding is consistent with other work that has shown that simply seeing or hearing information repeatedly does not enhance memory for this information (e.g., Berkerian \& Baddeley, 1980; Nickerson \& Adams, 1979; Rubin \& Kontis, 1983) and that remembering information entails more detailed semantic, analytical, and/or deeper levels of processing for 
Fig. 3 Percentage of participants who a did not know the location of the nearest fire extinguisher, b knew a location, but not the nearest location, and c correctly knew the location of the nearest figure extinguisher in the initial session

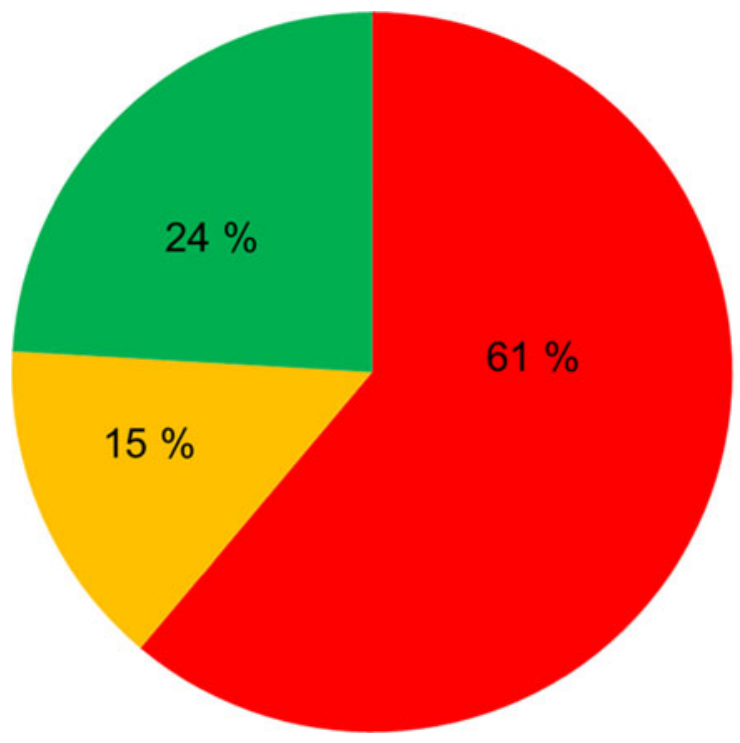

Did not know the location of the nearest fire extinguisher

Knew a location, but not the nearest location

- Correctly knew the nearest location information to enter long-term memory (e.g., Craik \& Lockhart, 1972; Craik \& Tulving, 1975). However, the present findings are remarkable given that fire extinguishers are bright red, placed in conspicuous locations, and have the potential to be lifesaving devices.

The results from the follow-up interview are shown in Table 1. Overall, people were especially good at remembering the location of other objects (e.g., clocks), even when they reported not using these objects very often (e.g., drinking fountain, floor map). Strikingly, people were especially poor at knowing the location of the fire alarm, with accuracy comparable to that for locating the fire extinguisher. The fire extinguishers were much larger in size and more frequent than the fire alarms (there were six fire extinguishers per floor, vs. two fire alarms per floor). Much like the fire extinguishers, fire alarms are bright red, placed in plain sight, and need to be located rapidly in an emergency but are poorly remembered. Moreover, unlike the fire extinguishers, which were rapidly found despite poor initial memory, participants may not have "seen" or "noticed" the fire alarms, as evidenced by the relatively long search times to locate the fire alarm, relative to other objects, including the fire extinguishers (see Table 1). Finally, after a 2-month retention interval, all participants remembered the location of the nearest fire extinguisher (see also Vo \& Wolfe, 2012), suggesting that the earlier failed retrieval (and/or selfrevelation that they did or did not know the location of the nearest fire extinguisher) served as an effective intervention that enhanced later memory for these lifesaving devices.

The present study showed that a large number of people failed to remember the location of the nearest fire extinguisher despite years of exposure to it, yet were able to locate a fire extinguisher fairly quickly and, in the followup session, could accurately remember the location of the
Table 1 Summary of the objects that were tested in the follow-up interview (and the number of objects located on each floor), the mean proportion of people who knew the correct location, mean confidence that they knew the location $(0=l o w, 10=h i g h)$, how frequently they used the object in the past $(0=$ never, $10=$ very often $)$, and the approximate amount of time it took to locate the object (as measured using time ranges of $<5 \mathrm{~s}, 5-10 \mathrm{~s}, 10-30 \mathrm{~s},>30 \mathrm{~s}$ ) (with standard errors of the means shown in parentheses, where appropriate)

\begin{tabular}{|c|c|c|c|c|}
\hline Objects (per floor) & Correct location & Confidence & Used in past & Time to find \\
\hline Floor plan map (3) & $.91(.05)$ & $7.8(0.5)$ & $3.6(0.4)$ & $5-10 \mathrm{~s}$ \\
\hline Clock (3) & $.80(.07)$ & $7.6(0.5)$ & $6.9(0.5)$ & $<5 \mathrm{~s}$ \\
\hline Drinking fountain (2) & $.96(.03)$ & $9.2(0.3)$ & $4.3(0.5)$ & $<5 \mathrm{~s}$ \\
\hline Fire alarm (2) & $.26(.04)$ & $3.3(0.6)$ & N/A & $5-10 \mathrm{~s}$ \\
\hline Fire extinguisher time 1 (6) (initial session) & $.24(.06)$ & $4.4(0.5)$ & N/A & $<5 \mathrm{~s}$ \\
\hline Fire extinguisher time 2 (6) (follow-up session) & $1.0(0)$ & $9.5(0.2)$ & $\mathrm{N} / \mathrm{A}$ & $<5 \mathrm{~s}$ \\
\hline
\end{tabular}

Note. In the initial session, after locating the fire extinguisher, people rated their confidence in finding the fire extinguisher at a future time $(M=$ 9.5). When we conducted the follow-up interview at time 2 ( 2 months later), peoples' mean confidence at time 1 was consistent with both their subsequent success at time $2(M=100 \%)$ and their rated confidence in locating the fire extinguisher at time $2(M=9.4)$ 
nearest fire extinguisher 2 months later. The ability to locate these objects might reflect mechanisms of attentional priority and goal-directed attention (e.g., Castel, McGillivray, \& Friedman, 2012; Yantis \& Johnson, 1990). Although people may not remember the location of the nearest fire extinguisher, they can locate a bright red object when this becomes goal relevant (hopefully, in the case of a real fire). It may be that when goals become activated, people can execute action-specific programs (e.g., Cañal-Bruland \& van der Kamp, 2009) that enable them to locate a previously unnoticed fire extinguisher. However, in the event of a fire, environmental and internal conditions (e.g., smoke in a hallway, anxiety, and stress), could potentially compromise perceptual and goal-relevant cognitive operations (cf., Vendetti, Knowlton, \& Holyoak, 2012), such that the person would need to rely on memory to find a fire extinguisher. The poor recall might also reflect failures of associative memory, since people know they have seen a fire extinguisher somewhere on their floor but have trouble remembering (and/or misremembering) the precise location with the object in question. Future work could examine whether people can both remember and locate emergency eyewash stations (especially in laboratory settings), since this may prove to be even more critical when vision is compromised, something that can easily happen when chemicals enter the eye. Given the findings of the present study, even when people have uncompromised vision, they often are not aware of the nearest location of a safety device. Our findings may also be relevant in highly stressful situations, such as finding an emergency exit on an airplane. Training protocols should consider that often people may encode information during training yet may not have immediate access to it when they need to spontaneously recall important information, possibly due to lack of attention during encoding, poor incidental learning, or rapid forgetting. Consistent with this possibility, the Federal Aviation Administration requires that, on flights longer than $4 \mathrm{~h}$, passengers be reminded of the location of emergency exits prior to landing.

The present findings emphasize the need for more work that assesses how cognitive processes function in complex, real-word settings, providing what can be considered a complementary approach for studying human cognition, one that has been referred to as cognitive ethology (e.g., Kingstone et al., 2005; Kingstone et al., 2003; Smilek, Eastwood, Reynolds, \& Kingstone, 2007). This approach emphasizes the observation and description of human behavior, as well as the personal and subjective reports that often accompany people's behavior (including their successes and failures), since people engage in tasks in realworld situations. In addition, the present "field study" also offers a relatively simple but powerful form of intervention training that may enhance memory for the nearest fire extinguisher. Specifically, participants in the initial session engaged in a form of errorful learning, often failing to know the location of the nearest fire extinguisher, but then finding it, which likely enhanced memory when tested in the 2month follow-up. This form of initial failed retrieval and retrieval practice (e.g., Bjork, 1994; Karpicke \& Roediger, 2008; Kornell, Hayes, \& Bjork, 2009; McGillivray \& Castel, 2010) could allow for the potent formation of an episodic memory (cf. Tulving, 1983) for the location of the fire extinguisher, thus acquiring information that could potentially prove to be lifesaving in the event of a fire. Participants in the follow-up interview all reported remembering having to find the fire extinguisher 2 months prior, suggesting that this initial "fire extinguisher drill" can enhance later memory. Similarly, recent work suggests that survival processing can enhance memory (e.g., Nairne \& Pandeirada, 2010) and that memory can and should be tuned to adaptive survival mechanisms, such as remembering the location of a lifesaving object. Asking people to search for a survival-relevant object during training may enhance the likelihood of finding this object during an actual fire. The present study demonstrates a form of inattentional blindness and amnesia for highly visible objects that, while not goal-relevant on a day-to-day basis, could potentially be essential to survival in an emergency.

Author Note This study was supported by ONR Grant N000140810186. We thank Airom Bleicher, Sabrina Lux, and Nicole Foley for help with data collection and Robert Bjork, Jacques Cerf, Michael Dodd, Barbara Knowlton, and Zili Liu for helpful comments.

\section{References}

Bartlett, F. C. (1932). Remembering: A study in experimental and social psychology. Cambridge, UK: Cambridge University Press.

Berkerian, D. A., \& Baddeley, A. D. (1980). Saturation advertising and the repetition effect. Journal of Verbal Learning and Verbal Memory, 19, 17-25.

Bjork, R. A. (1994). Memory and metamemory considerations in the training of human beings. In J. Metcalfe \& A. Shimamura (Eds.), Metacognition: Knowing about knowing (pp. 185-205). Cambridge, MA: MIT Press.

Cañal-Bruland, R., \& van der Kamp, J. (2009). Action goals influence action-specific perception. Psychonomic Bulletin \& Review, 16, $1100-1105$.

Castel, A. D., McGillivray, S., \& Friedman, M. C. (2012). Metamemory and memory efficiency in older adults: Learning about the benefits of priority processing and value-directed remembering. In M. NavehBenjamin \& N. Ohta (Eds.), Memory and aging: Current issues and future directions (pp. 245-270). New York: Psychology Press.

Craik, F. I. M., \& Lockhart, R. S. (1972). Levels of processing: A framework for memory research. Journal of Verbal Learning and Verbal Memory, 11, 671-684.

Craik, F. I. M., \& Tulving, E. (1975). Depth of processing and the retention of words in episodic memory. Journal of Experimental Psychology. General, 104, 268-294.

Intraub, H., \& Richardson, M. (1989). Wide-angle memories of closeup scenes. Journal of Experimental Psychology: Learning, Memory, and Cognition, 15, 179-187. 
Karpicke, J. D., \& Roediger, H. L. (2008). The critical importance of retrieval for learning. Science, 319, 966-968.

Kingstone, A., Smilek, D., Birmingham, E., Cameraon, D., \& Bischof, W. F. (2005). Cognitive ethology: Giving real life to attention research. In J. Duncan, L. Phillips, \& P. McLeod (Eds.), Measuring the mind: Speed, control \& age (pp. 341-358). New York: Oxford University Press.

Kingstone, A., Smilek, D., Ristic, J., \& Eastwood, J. D. (2003). Attention, researchers! It is time to take a look at the real world. Current Directions in Psychological Science, 12, 176180.

Kornell, N., Hays, M. J., \& Bjork, R. A. (2009). Unsuccessful retrieval attempts enhance subsequent learning. Journal of Experimental Psychology: Learning, Memory, and Cognition, 35, 989-998.

Loftus, E. F. (1992). When a lie becomes memory's truth: Memory distortion after exposure to misinformation. Current Directions in Psychological Science, 1, 121-123.

Mack, A., \& Rock, I. (1998). Inattentional blindness. Cambridge, MA: MIT Press.

McGillivray, S., \& Castel, A. D. (2010). Memory for age-face associations: The role of generation and schematic support. Psychology and Aging, 25, 822-832.

Nairne, J. S., \& Pandeirada, J. N. S. (2010). Adaptive memory: Ancestral priorities and the mnemonic value of survival processing. Cognitive Psychology, 61, 1-22.

Neisser, U. (1982). Memory: What are the important questions? In U. Neisser \& I. E. Hyman Jr. (Eds.), Memory observed (pp. 3-18). New York: Worth.

Nickerson, R. S., \& Adams, M. J. (1979). Long-term memory for a common object. Cognitive Psychology, 11, 287-307.

Rubin, D. C., \& Kontis, T. C. (1983). A schema for common cents. Memory \& Cognition, 11, 335-341.
Simons, D. J., \& Chabris, C. F. (1999). Gorillas in our midst: Sustained inattentional blindness for dynamic events. Perception, 28, 1059 1074.

Simons, D. J., \& Rensink, R. A. (2005). Change blindness: Past, present, and future. Trends in Cognitive Sciences, 9, 16-20.

Smilek, D., Eastwood, J. D., Reynolds, M. G., \& Kingstone, A. (2007). Metacognitive errors in change detection: Missing the gap between lab and life. Consciousness and Cognition, 16, 52-57.

Tulving, E. (1983). Elements of episodic memory. New York: Oxford University Press.

US Department of Labor Occupational Safety and Health Standards. (retrieved April 27, 2012) http://www.osha.gov/pls/oshaweb/ owadisp.show_document?p_table=STANDARDS\&p_id=9811

Vendetti, M., Knowlton, B. J., \& Holyoak, K. J. (2012). The impact of semantic distance and induced stress on analogical reasoning: A neurocomputational account. Cognitive, Affective, \& Behavioral Neuroscience. doi:10.3758/s13415-012-0103-0

Vo, M. L.-H., \& Wolfe, J. M. (2012). When does repeated search in scenes involve memory? Looking at versus looking for objects in scenes. Journal of Experimental Psychology. Human Perception and Performance, 38, 23-41.

Wolfe, J. M. (1998). Visual memory: What do you know about what you saw? Current Biology, 8, R303-R304.

Wolfe, J. M. (1999). Inattentional amnesia. In V. Coltheart (Ed.), Fleeting memories (pp. 71-94). Cambridge, MA: MIT Press.

Wolfe, J. M., Alvarez, G. A., Rosenholtz, R. E., \& Kuzmova, Y. I. (2011). Visual search for arbitrary objects in real scenes. Attention, Perception, \& Psychophysics, 73, 1650-1671.

Wolfe, J. M., Horowitz, T. S., \& Kenner, N. (2005). Rare items often missed in visual searches. Nature, 435, 439-440.

Yantis, S., \& Johnson, D. N. (1990). Mechanisms of attentional priority. Journal of Experimental Psychology. Human Perception and Performance, 16, 812-825. 